\title{
Intrapancreatic accessory spleen: a rare cause of recurrence of immune thrombocytopenic purpura
}

\author{
Francisco García Angarita ${ }^{1}$ \& Alfonso Sanjuanbenito Dehesa ${ }^{2}$ \\ ${ }^{1}$ Hospital Universitario Ramón y Cajal, Madrid, Spain \\ ${ }^{2}$ Department of Bilio-Pancreatic surgery, Hospital Universitario Ramón y Cajal, Madrid, Spain
}

\author{
Correspondence \\ Francisco García Angarita, Hospital Ramón y \\ Cajal, Ctra. de Colmenar Viejo, km. 9,100, \\ 28034 Madrid, Spain. Tel: 0034679922672 ; \\ Fax: 0034913368000; E-mail: \\ frnjgarcia@gmail.com
}

\author{
Funding Information \\ No sources of funding were declared for this \\ study. \\ Received: 14 January 2016; Revised: 7 April \\ 2016; Accepted: 3 July 2016
}

Clinical Case Reports 2016; 4(10): 979-981

\section{Key Clinical Message}

Accessory splenectomy should be considered in any patient with recurrence of immune thrombocytopenic purpura, if studies (scintigraphy using heatdamaged Tc99m-labeled red blood cells) are suggestive of residual functional splenic tissue. The most common benefit after removal of accessory spleen seems to be the reduction of dose in medical treatment.

\section{Keywords}

Accessory spleen, immune thrombocytopenic purpura, laparoscopic splenectomy, recurrence.

doi: $10.1002 / \mathrm{ccr} 3.642$

\section{Introduction}

Excluding trauma, immune thrombocytopenic purpura (ITP) is the most common indication for splenectomy, being an attractive therapeutic option for those patients with no response after 4-6 weeks of medical therapy with steroids or other agents [1]. At least $15 \%$ of patients treated with splenectomy will develop recurrence of ITP after surgery. The prevalence of accessory spleen tissue is about $10-40 \%$ of autopsies [2] and does not require treatment unless it is associated with hematological diseases. In the context of immune thrombocytopenic purpura, accessory spleens can cause recurrent or persistent disease after splenectomy, and, in this cases, exeresis of accessory spleen is indicated in order to maintain an acceptable platelet count and to reduce the pharmacological treatment.

\section{Case Report}

A 44-year-old woman, with a medical history of primary biliary cirrhosis and asymptomatic HBV infection, was admitted to our clinic because of development of thrombocytopenia (platelet count of $19.000 / \mathrm{microL}$ ) and skin purpura since one year.
The patient did not show any alteration on physical examination, except for the isolated skin purpura in upper extremities, abdomen without mases, and low platelet count with no other disorder in blood sample. The imaging tests we performed before establishing the medical treatment were an abdominal ultrasonography and computed tomography (CT), demonstrating no spleen or liver disorders. First-line treatment with orally steroids was started, showing a transitory response in her platelet count, with thrombocytopenia relapse in few months. Considering the lack of response with high dose of steroid treatment, surgery was proposed as next step. Then, laparoscopic splenectomy (pneumoperitoneum was created using a Veress needle, and four trocars were placed in left subcostal region) was accomplished successfully without intraoperative evidence of accessory spleen (abdominal cavity was explored in order to search for the presence of accessory spleens in their most common locations), and the specimen was introduced into a retrieval bag $(800 \mathrm{~mL})$ for removal by morcellation. No postoperative complications were described.

After surgery, the patient showed a platelet increase in the first few weeks with subsequent relapse in platelet count with $<20.000$ platelets/microL after 45 days of 
procedure, requiring treatment with thrombopoietic drugs (eltrombopag) in order to maintain platelet count and to avoid bleeding symptoms.

Research of the cause of ITP recurrence started 3 months after surgery with nuclear medicine scintigraphy using heat-damaged Tc99m-labeled red blood cells, revealing two images of uptake in left subdiaphragmatic region (Fig. 1), compatible with two accessory spleens, not previously diagnosed in preoperative studies.

A second intervention was proposed and the patient underwent intraoperative gamma-probe guidance surgery after injection of Tc99m-labeled denatured erythrocytes, through left subcostal minilaparotomy. Systematic scan of the left upper quadrant was performed, with care taken to angle the probe away from the liver so as to avoid interference. Higher activity was noted next to the tail of the pancreas where the exploration revealed a soft red mass embedded in the pancreatic tail (Fig. 2) and another one in the retrocolic fatty tissue. Resection of two accessory spleens was completed and no complications were described after the procedure. The histological study confirmed the presence of splenic tissue in both pieces. The patient did not present an immediate increase in platelet count, so thrombopoietic treatment was needed again for 3 months. Nowadays, with lower doses of steroids treatment, platelet count remains stable.

\section{Discussion}

The response rate of splenectomy in patients affected with ITP is around $70 \%$. An estimated $15-30 \%$ of patients show relapse after surgery, and at least one-third of these relapse is due to accessory splenic tissue [1].

The sensitivity and specificity of CT scan for the detection of accessory spleen are 60 and 95.6\%. Preoperative

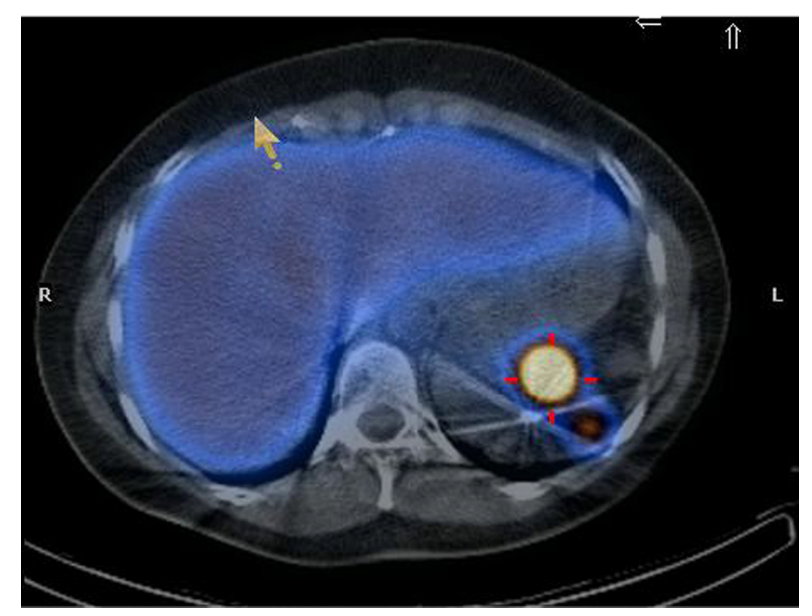

Figure 1. Gammagraphic study with red blood cells and Tc99m with image of abdominal computed tomography overlapped.

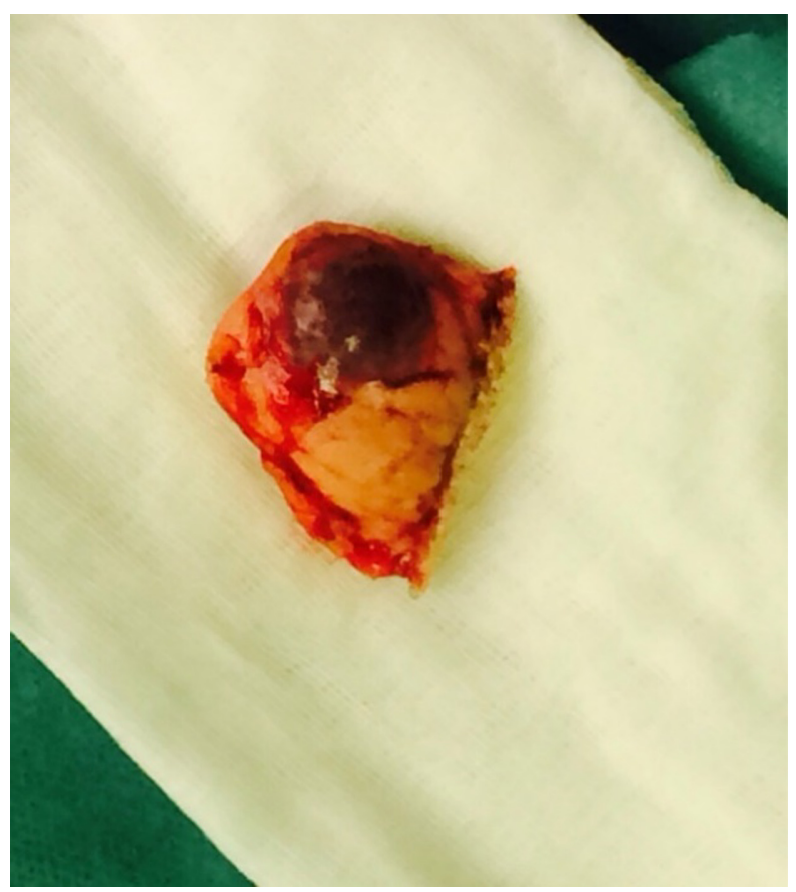

Figure 2. Intrapancreatic spleen after removal.

CT scan for their detection and localization may not be necessary [3]. Intrapancreatic accessory spleens are relatively uncommon and can be difficult to distinguish from pancreatic neuroendocrine tumors on CT scan and magnetic resonance imaging. Tc99m heat-denatured red blood cells can distinguish accessory spleens from neoplasia because of prominent physiological uptake in functioning splenic tissue, being useful in order to avoid unnecessary biopsy or major abdominal surgery if pancreatic neoplasia is not suspected [4]. Intrapancreatic accessory spleens, as other accessory splenic tissue, can cause recurrence of ITP and, if the study with nuclear medicine confirms the diagnosis, excision in this case is indicated.

Accessory splenectomy should be considered in any patient with recurrence of ITP if studies are suggestive of residual functional splenic tissue. It appears that response rates after laparoscopic removal of retained splenic tissue are at least comparable with an open approach [5]. Results in clinical response show that less than one-quarter of these patients will have a long-term remission after the removal of an accessory spleen, and this is probably due to increased destruction of platelets by accessory parts of the reticuloendothelial system other than the spleen [6]. The most common benefit after removal of accessory spleen seems to be the reduction of dose in medical treatment.

In literature, we find different results after accessory splenectomy. In case of open splenectomy, Akwari et al. [7] 
described nine patients undergoing open accessory splenectomy for recurrent ITP, showing complete remission in six patients. In laparoscopic approach, Szold et al. [8] describe successful laparoscopic accessory splenectomy in eight patients with recurrent ITP. None experienced complete response, with two having partial remission. Leo et al. [9] propose that surgical accessory splenectomy allows a transitory remission of the disease, after a study with two patients who underwent laparoscopic accessory splenectomy for recurrence of ITP. The first patient had a disease-free period of 2 months and the second one of 1 month. Both patients restarted immunosuppressive therapy.

In our case, minilaparotomy was the selected approach due to the rare location of accessory spleen that we suspected in preoperative imaging studies. A minilaparotomy in the left subcostal region allowed us to use the gammaprobe to detect the splenic tissue and to remove it through the same incision.

Evolution in our patient shows a moderate response after the removal of accessory spleens, which is a result often described as the most common situation after the surgical management of accessory spleen in the context of ITP.

\section{Conclusion}

Based on literature and on our case, we recommend the excision of accessory spleen in case of recurrence in hematological disease, because a minimally invasive approach removal (laparoscopic or even minilaparotomy with gamma-probe guidance) is safe and can be beneficial to patients with recurrent ITP and documented accessory splenic tissue, although response usually is not durable and satisfactory. Accessory spleen diagnosis can be safely achieved with scintigraphy using heat-damaged Tc99mlabeled red blood cells.

\section{Conflict of Interest}

None declared.

\section{References}

1. Choi, Y. U., E. P. Dominguez, V. Sherman, and J. F. Sweeney. 2008. Laparoscopic accessory splenectomy for recurrent idiopathic thrombocytopenic purpura. JSLS 12:314-317.

2. Radu, C. C., G. Muţiu, and O. Pop. 2014. Accesory spleen. Rom. J. Morphol. Embryol. 55(Suppl. 3):1243-1246.

3. Quah, C., G. D. Ayiomamitis, A. Shah, and B. J. Ammori. 2011. Computed tomography to detect accessory spleens before laparoscopic splenectomy: is it necessary? Surg. Endosc. 25:261-265.

4. Barber, T. W., A. Dixon, M. Smith, K. S. Yap, and V. Kalff. 2016. Ga-68 octreotate PET/CT and Tc-99 m heatdenatured red blood cell SPECT/CT imaging of an intrapancreatic accessory spleen. J. Med. Imaging Radiat. Oncol. 60:227-9.

5. Antevil, J., D. Thoman, J. Taller, and M. Biondi. 2002. Laparoscopic accessory splenectomy with intraoperative gamma probe localization for recurrent idiopathic thrombocytopenic purpura. Surg. Laparosc. Endosc. Percutan. Tech. 12:371-374.

6. Woo, J. H., S. H. Park, Y. K. Park, C. B. Choi, Y. Y. Choi, M. J. Ahn, et al. 2004. Postsplenectomy recurrence of thrombocytopenia with an accessory spleen. Korean J. Intern. Med. 19:199-201.

7. Akwari, O., K. Itani, R. Coleman, W. F. Rosse, et al. 1987. Splenectomy for primary and recurrent immune thrombocytopenic purpura. Current criteria for patient selection and results. Ann. Surg. 206:529-551.

8. Szold, A., M. Kamat, A. Nadu, and A. Eldor. 2000. Laparoscopic accessory splenectomy for recurrent idiopathic thrombocytopenic purpura and hemolytic anemia. Surg. Endosc. 14:761-763.

9. Leo, C. A., R. Pravisani, S. Bidinost, U. Baccarani, V. Bresadola, A. Risaliti, et al. 2015. Postsplenectomy recurrence of idiopathic thrombocitopenic purpura: role of laparoscopic splenectomy in the treatment of accessory spleen. G. Chir. 36:153-157. 